\title{
Negotiating identity transition when leaving forensic hospitals
}

Word Count: 8116 main body, 9416 total

Dr Michael Coffey, Senior Lecturer, Department of Public Human and

Policy Studies, Swansea University, Singleton Park, Swansea SA2 8PP

This is the pre-print post peer review version of the paper published as Coffey, M. (2012) Negotiating identity transition when leaving forensic hospitals Health: An Interdisciplinary Journal for the Social Study of

Health, Illness and Medicine 16: 489-506 doi:10.1177/1363459311434649

The final and definitive version can be found by following the link below http://hea.sagepub.com/content/16/5/489.abstract 


\section{Biographical Note:}

Michael Coffey is a senior lecturer at Swansea University. His research interests centre on the delivery and organisation of mental health services with particular reference to multiple perspectives. Key areas of interest include the division of labour, policy in complex systems and recipient experiences of health and social care delivery. 


\section{Negotiating identity transition when leaving forensic}

\section{hospitals}

\section{ABSTRACT}

The transition from hospital patient to community resident is something which is far from straightforward. For those with multiple labels of disability, chronicity and criminal offending behaviours this transition is particularly complicated. This paper reports on a study of accounts provided by a hard-toreach group of patients and their workers in one region of the UK. Through the use of 59 in-depth interviews with conditionally-discharged persons, community mental health nurses and social workers, everyday understandings of the process of discharge and reintegration were investigated. The primary focus was on how identity was handled in the talk of discharged persons and what workers said about this. Analysis focused upon the action-oriented nature of accounts related to discharge, community return and attempts to construct viable identities in the outside world. This study found that stories did the work of loosening previous labels. Illness as mitigation was deployed as an important resource for this purpose. Deviant labels signifying mental illness and criminality presented enduring identitythreats. It was found that as they adjust to return to the community, individuals deploy particular types of identity talk to neutralise ascriptions of continuing deviance and make claims to normality. Workers for their part supported illness as mitigation but continued to orient towards risk as an enduring identity label. In their day-to-day lives the accomplishment of 'ordinary' identities was a continuing task of discharged persons in 
maintaining community return.

Keywords: UK; identity; mental health, transition; conditional discharge

\section{INTRODUCTION}

The safe and successful re-integration of mentally-ill offenders on discharge from hospital is a main concern for community forensic mental health services. The focus of much of the research literature in this field has centred upon risk and recidivism. There has been less attention paid to how this population attempt to achieve accommodations and transition towards nondeviant status. Detention in a forensic setting implies both serious criminal offences and mental illness, signalling the availability of overlapping deviant labels (Becker, 1963; Lemert 1972). Mental illness labels in effect allude to and can be interpreted as a collective understanding of the kind of person someone 'really' is, indicating the need for social control. These labels provide at once a description of the person's position in society and a profile of the type of character they are understood to be.

Forensic mental health settings in the UK are in the main geographically remote and hospital admission is likely to be counted in years rather than months (Maden, Curle, Meux, Burrow \& Gunn, 1993). The challenges of achieving valued roles for those leaving these facilities are exacerbated by prolonged detention and long distances from home which disconnect people from social networks. Discharge from forensic mental health settings is often conditional upon agreeing to this monitoring hence the term 'conditional 
discharge' and includes the legal means to recall the person to hospital (The Mental Health Act, GB Department of Health 1983). Conditions of discharge may include limits on travel, curfews, abstinence from recreational drugs and alcohol, attendance for appointments and structured day-time activity as well as compliance with medication and treatment regimes. Aftercare teams consisting of nurses, social workers and psychiatrists provide ongoing support post-discharge to the person through regular domiciliary visits. These visits also allow monitoring and supervision of the person's mental condition and risk behaviours by aftercare teams, police and social services. The intention is to manage the potential risk posed by the person and if necessary to enforce their swift return to hospital.

Conditionally discharged individuals must negotiate new beginnings in communities which may prove unwelcoming. For example, Farmer (1996) has used the term structural violence to refer to the combined negative effect of social, economic and political factors upon the health and well-being of individuals. This combination of factors shapes both the context for the development of ill-health and how it is responded to by health and social care providers. Structural violence has particular relevance for phenomena such as mental ill-health. For instance, Kelly (2005: 722) has argued that problems associated with mental ill-health such as social exclusion, homelessness and violation of human rights are related to the ways mental illness is "patterned, interpreted and treated by societies" rather than a consequence of the condition itself. Deviant labels and structural violence are then hurdles which discharged people must contend with while attempting to reintegrate into the 
wider social group.

There is limited evidence of how recipients of conditional discharge attempt reintegration. Studies on this aspect of forensic psychiatry focus upon recidivism and recurrence of risk behaviours in the form of untoward violent events (Gibbens and Robertson, 1983). Illuminative as these studies undoubtedly are, there is no attempt to provide a picture of the lives of people following discharge and the work they do to re-integrate. As a consequence we are missing important information on how participants themselves work to achieve new identities on community return. For instance it would improve our understanding of these processes to explore how identities are managed, deployed and negotiated within the context of community return.

\section{ACCOUNTS}

Accounts including stories and narratives are a means by which actors provide explanations to others and in doing so display culturally embedded normative understandings (Orbuch, 1997). Producing an account in a research interview setting can be seen as a performative act which by its very nature is an interaction. Research interviews are different to naturally occurring interactions in many respects but they have similar qualities in that they are occasioned by the dealings between persons. It is difficult to be certain how what is said in these circumstances relates to events in everyday settings but it is clear that accounts are often required and offered in interaction (Scott and Lyman, 1968). These accounts have rhetorical power aiming to persuade or convince the listener. They can also function to argue, 
resist or challenge competing accounts and provide alternative ways of describing things (Edwards 1998). Accounts function as biographical warrants and involve specific self-interested claims which due to their firsthand nature make them difficult to dispute or challenge. Biographical accounts organise life events so they are consistent, reciprocally meaningful and functional parts of the whole (Jarvinen, 2000).

A discursive analysis of accounts can indicate the social action towards which stories are directed. Narratives of life events told by actors include various claims including identity and recovery. Story-telling is influenced by context, ritual, performance, audience, culture, memory, ordering, motives, moral concerns and interacting. Narratives produced for the purposes of a research interview are one version of experience and their validity stems not from any claims to access some embedded singular truth but rather from the point that it is issued by one protagonist, in the story - it is as valid as other versions but not more so. Atkinson (1997:333) argued that the "biographical warrant" of narrative does not provide a hyper-authentic version of actors' experiences or selves. Such a claim is a distraction in that it directs attention away from what actually may be of interest in stories. In Atkinson's view once we accept that stories show orientation in the ways described above then this opens up for analysis the practices via which narratives are achieved in the talk of actors. Analysis of accounts can reveal the social purposes that talk is put to.

Accounts are one way in which persons articulate views on events in their lives, how they orient towards particular occurrences and the work that they 
are warranted to do. Analysis of talk in the form of personal narratives of people leaving forensic settings can provide new understandings about identity, community return and recovery. For instance, deviant identity labels are warranted in social situations where illness and criminal offending occur. In such circumstances actors account for these labels and participate in new identity work through the medium of talk in interaction. Stories are one way of achieving this work and enable social actors to do the work of accounting. Accounting therefore has a social function. It enables the person to articulate versions of their experience, to communicate oriented-to identities and establish their moral worth. Discourse then provides a medium through which identity is "accomplished, disputed, ascribed, resisted, managed and negotiated" (Benwell and Stokoe, 2006:4).

Accounts are produced by members for one another in such a way as to be appreciated, understood and analysed by others for the purposes of subsequent action. Utterances can be seen as 'conventionally grounded social actions' (Heritage and Atkinson, 1984:5). Accounts work to regulate social relationships and are not simply telling it how it was but seek to argue, agree, challenge or persuade. As such they do important work and provide a useful means for examining displays of understanding.

One quality of accounts where participants may be subject to evaluative responses is the sensitive nature of identity performance. Socially-sensitive topics are those which have implications for the individual or the class of people represented by an individual (Sieber and Stanley, 1988). Social actors 
may wish to manage what Lee (1993) referred to as threats. These threats can be to participants, their families, elites who exercise power and control or society at large. Lee (1993) argues that the level of threat is less associated with the precise topic of the research and more to do with the relationship between the topic and its social context.

There appears to be dual concerns operating when accessing forensic mental health settings; those of service users themselves and those of workers. For service users there may be concerns about the proximity to an identity that effectively sees them "disqualified from full social acceptance" (Goffman, 1963:9). There are also concerns about reliving distressing and traumatic life events (Brannen, 1988). Concerns for workers relate to a tradition of shielding information from public view in these settings. Historically this was embodied in the requirement for workers to sign the Official Secrets Act (Mercer and Mason, 1998). This combination of concerns makes it very difficult as an outsider to conduct research which examines insitu identity negotiations such as interactions or as a participant observer. An alternative is to provide participants with the opportunity to provide an account and to use this data to analyse the functions or purposes these narratives are deployed for (Edwards, 2006).

Studies of the application of illness versus deviance/criminality labels have tended to focus on the actions of professional labellers. The research reported here adds a rare case study of orientation to such identities in talk about self. It looks specifically at the interview situation, illustrating that former forensic 
psychiatry patients are capable of fine attention to culturally available identities and the inferences and actions likely to flow from identity ascriptions.

\section{METHODS}

In treating talk as action-oriented, and therefore functional, this study views verbal communication as constitutive of social action. Talk is seen as a means for accomplishing socially relevant actions. The study was informed by the ethnomethodological stance of seeking to explore people's own displays of their understandings of life events (Garfinkel, 1967), as produced in talk. Identity, as one such display, was seen as an ongoing accomplishment of social actors in everyday life. The aim of this study was to examine how discharged patients accomplished community return in the form of identity claims and transition. The approach was to examine everyday understandings in accounts of conditionally discharged patients and their workers from two forensic mental health settings in the UK. A multiple perspectives approach in which both worker and patient accounts are analysed can provide the opportunity to examine the differing views and separate stances of a vulnerable group and those working with them. The potential of this approach is that it makes available for analysis the separate stances on identity taken by workers and patients.

This study used research interviews to collect accounts of conditional discharge from a hard-to-reach group of patients and their workers. Patients were 'hard-to-reach' in the sense that access for the purposes of research was highly controlled by multiple gatekeepers who were keen to prevent 
further unwanted publicity related to previous high profile offences. Interview data were treated as situated interactions used to provide an analysis of actor's displays of everyday understandings (Stanley and Billig, 2004). The intention was to examine how the accounts functioned to achieve identity claims. Ethical approval for this study was obtained from two local research ethics committees (one for each setting) prior to data collection.

Ethical concerns in this field include questions of capacity to give informed consent, the validity of consent when detained, issues of control, power, privacy and confidentiality with the potential for exploiting for research purposes a literally captive audience (Adshead and Brown, 2003). Capacity can be defined as the ability to exercise autonomy and independent decision making. Mental illness is one area where it can be argued that capacity may be said to be impaired or disturbed either temporarily or long term. Mental illness does not however preclude people from offering clear, valid and objective perspectives on the services they receive or in comprehending and giving informed consent to participate in research (Carpenter, Gold, Lahti, Queern, Conley, Bartko, Kovnick \& Appelbaum, 2000). This study was mindful of the ethical implications of research in this field and paid due attention to these concerns throughout.

\section{Data collection and handling}

Negotiating and maintaining access to the research settings was an ongoing process throughout this study and is described in detail elsewhere (Coffey 2008). Service-user participants were recruited through information sheets 
which were passed to them by workers. These information sheets explained the purpose of the study that participation was voluntary, that participants were free to withdraw without consequence and asked them to contact the researcher if interested in participating. Written informed consent was then obtained from all participants prior to interview. Workers were approached to participate following the completion of service-user participant interviews.

\section{Characteristics of the sample}

The research sample was drawn from two forensic mental health services in one region of the UK. In all instances service-user participants had previously been detained on Section 37 and remained subject to Section 41 of the Mental Health Act 1983, which provides for restricted and conditional discharge. The purposive sampling criteria included; men and women (over the age of 18 years) with mental health problems and experience of recent or prolonged conditional discharge. The aim was to gain a sample of service users who would speak about experiences of different post-discharge phases.

In total twenty-nine people were approached for interview and twenty (18 men and 2 women) agreed to participate. Twenty workers (nurses and social workers) providing aftercare were also interviewed. Some participants were interviewed more than once resulting in fifty-nine interviews.

Most interviews with patient participants took place in their own homes and with workers in their offices. All interviews were audio-recorded and transcribed. Participants were asked to tell their story of leaving hospital. The 
actual question posed was a variation on the following, 'please tell me the story of leaving hospital and coming to live in the community again'. The aim was to allow participants to prioritise what they said and how they said it without imposing the researcher's presuppositions of what was important to tell.

All interviews were audio recorded and transcribed for analysis. Conventions for transcribing vary across the social sciences literature and the approach in this study was in line with Atkinson (1995:12) who noted that a

"tension between readability and fidelity is a recurrent issue for ethnographic analysis and there is no pure or perfect mode of representation".

Atkinson (1995) argued that in general studies of talk, care has to be taken to ensure transcription symbols don't make what is said unreadable and ultimately detract from, rather than inform, analysis. This may be particularly the case in studies of social actors own understandings of everyday practices. The aim was to achieve transcriptions for the intended purpose of examining stories and the work that these were used to accomplish. Standard spelling and punctuation is used where possible to make what was said intelligible. The intention is to remain faithful to what was said by participants rather than aiming for the "illusory fidelity of over-detailed and unreadable textual representations" (Atkinson, 1995: 13). Pauses are noted in brackets within extracts where these were timed to the nearest complete second. The purpose here was to contribute to an understanding of the pace of delivery of accounts and to facilitate judgements about their significance. 
Analysis of the transcripts focused primarily on service-user accounts of community return and the action-oriented nature of their talk. The focus of analysis was to examine what was being said, what it worked to accomplish and how this was achieved (Edwards, 2006). This involved examining what speakers prioritised in their talk such as establishing identity claims and how utterances worked to achieve this. This is in line with Edwards and Potter (1992) who argue that a discursive action approach positions language as representation subordinate to language as action. Workers accounts were then examined along similar lines with particular attention to examples of how these contrasted with the patient's account.

Participant names used in the following analysis are pseudonyms created to maintain anonymity.

\section{FINDINGS AND ANALYSIS}

Research interviews in this study ranged in length from the shortest at twentyfive minutes with a nurse participant to the longest at over two hours with a service-user participant. This provided a total of 55 hours of recorded interview time. The transcribed research interviews amounted to over 350,000 words in fifty-nine separate documents.

The initial route to a forensic mental health facility for participants was through the judicial system and participants' stories recounted transfers from prison or courts to hospital. These stories describe, what for many, was the first formal encounter with the police, courts and prison systems. These were emotionally 
difficult events experienced within the context of mental distress. Handling this potentially sensitive information within a research interview is a functional task of the narrative. Serious criminal offending and mental illness are liable to be labelled deviant and have implications for social identity. The following analysis will show how these deviant identities were accounted for by participants and how resources for laying-out exit routes from these identities were mobilised.

\section{IIIness as mitigation}

Participants explained initial contact with forensic services in terms of illnessrelated behaviours. These accounts described a sequence of events in which mental distress was present and unresolved prior to the criminal offences being committed. It is worthy of note that at no time were participants asked for information about their illness, hospitalisation or criminal convictions. The production of these accounts was instead occasioned by the context of accounting for their current living situation.

The following extract is taken from an interview (lasting approximately one hour) with Maeve who had left hospital only months before. Maeve described a time, following a serious suicide attempt, when a period of recovery in a local general hospital had come to an end. The account worked sequentially to establish the presence of unresolved illness as a key explanatory device for criminal offences.

P: Before I went to [medium security hospital] there was a lot of issues. I had a lot of therapy, intense therapy (2) which was really hard. Umm I had that once a 
week for about three and half years (1) sometimes more umm, which I had to go through all my past and everything and (1) sometimes I used to think, oh God I can't I can't cope with this. Sometimes I hurt myself after sessions and then it got easier and easier you know. As long as I knew people weren't judging me ... l'd been going for about 10 years. I was hardly ever out of hospital umm (2) and then umm I jumped off a bridge and umm (2) I was in hospital for a good while. Anyway I was still in plaster and they said to me you're going home now. I was living in a house, I couldn't get up and down the stairs, my bathroom was upstairs so I couldn't have got up and down to go to the toilet umm you know, and they just didn't seem to care. I couldn't even go to the shop you know or anything because it was too far away from where I live and I had no one at all and umm they were sending me home. I had no money either. I had no electric and gas, it had been cut off because of the time I was in hospital so I went in my bedroom in the hospital and set fire to the bed. (1) I was going to go to prison (2) until I saw umm a consultant from [medium security hospital] and I talked to her for about 7 hours on two occasions about all my past and everything and she said I think we can offer you a place..

[Maeve: Setting 2: lines 118-138] Maeve works to establish that there have been significant problems in her life leading to events that were retold in the interview. These problems required not just therapy but "intense therapy". This qualification of therapy as "intense" functioned to set-up the unfolding sequence of the story which established the seriousness of an already present condition. As we shall see below with Brendan this is something that participants were keen to establish. The sequence followed with a reference to how therapy was no easy option, it was "really hard". Therapy occurred frequently and over a prolonged period of time. This therapy involved going over past events and Maeve embellished 
the "issues" mentioned earlier with the phrase "I had to go through all my past and everything". This turn functioned to provide an explanatory backcloth to the story that followed. The sequential organisation of talk provided a convincing account of problems requiring professional intervention, further supported by her report of self-harming behaviours. Maeve then makes relevant the presence of competing, less positive accounts that might be available for instance, people "judging" her. The story challenged alternative competing accounts by outlining Maeve's commitment to addressing her problems by what was framed as prolonged and difficult exposure to therapy.

Maeve outlined a problem with the events experienced in that she was "still in plaster", when told she was being discharged. The problem signalled by the use of "still" was then further elaborated so that it was to be understood that a proposed return home after a long admission presented a number of functional complications for her. These included problems with access to bathroom, toilet and shopping facilities as well as having no money, gas or electricity. Maeve's account constructed events as placing her in an impossible position. "Still in plaster" can be read as accessing commonly available knowledge of reduced mobility and consequent problems with access to facilities. Notions of reduced mobility may be more readily understandable than those of mental distress. It was a very persuasive account in this regard and structurally provided the space within the narrative for describing the criminal offence. This was framed as a further consequential sequence of events, "so I went in my bedroom in the hospital and set fire to the bed". 
Untoward events framed within the context of inability to cope and an already present mental illness can also be seen in Lloyd's account. He was a man in his late thirties and from a rural background. In this account Lloyd makes use of similar resources to Maeve but also works to move towards asserting his difference from others who might be similarly labelled.

P: Well what I did was in (2) year 2001 (1) I burned the farm down like, I am telling you the story of it. And I burned the hayshed as well (2) my father went into hospital as well so I burned the farm after all that, after my father went into hospital. I was on my own and I didn't know what to do with the animals and stuff and I was called up by the police to go to [name] hospital. I was there for 5, 6 months (2) am I going too fast for you?

I: No that's [alright

P: And] umm they shifted me up to [distant district] then to [secure unit], ... I was there for two and half years (3) then they said I could come down to [secure unit] .... and since that l've gone through hell like. (1) Because when I was in [distant district] there was lots of people, well criminals there that killed somebody and all that. But then you know I haven't done that like so it's not fair that you're in with somebody like that then, its hard then in a way like. (2) Some of the cases were very bad. (7) There's a bit of information there for you (1). It's a long story but I know l've done wrong but my brothers and sisters and my family don't do nothing with me anymore.

[Lloyd: Setting 1: lines 26-47]

The talk produced in these stories have the form of an account which Scott and Lyman (1968: 46) define as a "linguistic device employed whenever an 
action is subjected to valuative inquiry". Orbuch (1997) has widened this definition to include other forms of stories or narratives which are seen to provide insights into embedded normative explanations. Both Maeve and Lloyd's accounts however have the form of situated standardised forms of talk that can be routinely expected when behaviour falls outside expectations (Scott and Lyman, 1968).

Maeve and Lloyd accounted for their actions as consequential responses to stressful life events in the presence of an existing mental condition. Firesetting is untoward and outside of expectations. Statements of untoward or deviant behaviour may lead to fractures in relations and jeopardise interaction. Accounts are one way of dealing with this problem. Their stories can be read as providing a particular type of account which Scott and Lyman (1968) refer to as an excuse. Excuses are socially approved vocabularies for mitigating responsibility. They are a form of account in which social actors accept an act as bad or wrong but avoid acceptance of full responsibility for the act. In foregrounding illness explanations the accounts work to establish mitigation for untoward behaviours. This is perhaps not unexpected but its importance is the way in which it opens a route to accomplishing claims to ordinary identities later in the account. Essentially it locates the speakers on the illness branch of the mad versus bad dichotomy. Sticky though this particular label is it nevertheless provides the opportunity to construct the moral self in the story. This opportunity is taken by demonstrating a commitment to following treatment advice and working towards recovery. 
In the following extract Maeve's social worker indicated that the illness designation was a common understanding and one which he sees as having a positive effect in that it allowed access to Section 41 aftercare.

$P: \ldots$ she sees it absolutely as a positive benefit and a positive benefit in the guarantee it gives her (1) the guaranteeing and the issue of course if you look at her offending, the issue about the offending was, she goes into hospital we're all, oh she's back again, we can't ever lift this woman out of depression, she just harms she self harms she wants more than we can give, you know what I mean. But what the 41 does is you have to give that service, yeah you are ill you do need it and what has been brilliant for her, she wants it, it validates her....

[Social Worker: Setting 2: lines 264-274]

Scott and Lyman (1968) note that accounts offered in mitigation may be honoured or not honoured by other social actors. This depends on background expectancies which refer to taken-for-granted ideas shared by social actors and which might be understood as information that everyone is said to know. Accounts offered by one person and honoured by other social actors may more clearly be seen within interactions between those parties although it was evident in the accounts of participants in research interviews for this study. These accounts show that participants share similar background expectancies concerning the effects of social and mental health problems and the outcomes associated with them.

Participants rely on these cultural understandings to support their claims to the sickness label (Parsons 1951). However the classic concept of the 'sick role' is somewhat tempered by the contested nature of modern psychiatric care and 
assumptions that medicine can provide the treatment necessary for the patient to follow (Breggin, 1993; Double, 2002; Crossley, 2006). While the person is expected to seek and follow treatment advice there are no guarantees that in doing so they will actually get better. In seeking medical warrants for sickness behaviours and the temporary exemptions from social roles that this may involve, people on conditional discharge demonstrated recurrent interactive activities of talk and accounting which have the social function of establishing moral rights to patient status. It is important to note that although participants were not asked about their illness or their offending histories in this study they nevertheless were approached as patients of forensic psychiatric services living outside of hospital on conditional discharge. This provided the context for the research interview and for participants the background expectancy may have been that an account was required. Stories therefore accomplished the business-in-hand of accounting for past actions by foregrounding illness explanations.

One way in which this is achieved is to make use of warrants provided by authority figures within the criminal justice and psychiatric professions. In the following extract Brendan achieved this with reference to his claim to be ill and to an extent this was honoured in the account of the community psychiatric nurse (CPN).

P: So I goes up to [high security hospital] and I honestly thought well they'll throw the key away you know I mean lets be fair like I know its diminished responsibility and I know I'm fully aware that I was ill at the time if you know what I mean and everybody else was bar the prosecution barrister if you know what I mean, that um psychiatrist and that.

[Brendan: Setting one: lines 48-52] 
$P$ : If [Brendan] is well (2) he isn't deemed a risk at all to others or to himself but because his mental state deteriorates quite quickly there is obviously the potential then for him to be very risky you know given the index offence...

[CPN: Setting one: 129-132]

Brendan's story like many others demonstrated awareness of other possible claims and moved to negate these by establishing moral claims to patient status. The story of illness was upheld in the CPN account, "his mental state deteriorates quite quickly". This account also invoked the spectre of risk giving weight to past events and their power in an imagined future (Annandale, 1996).

Stories told by patients frequently invoked official warrants, in the form of medical diagnosis or official opinion, to establish claims to be treated as ill and therefore not liable to be held fully responsible for their actions. These warrants substantiate the claim to patient status and, in the context of mitigation for their actions or in handling the potential socially sensitive identity threats that might be otherwise available, they represent a necessary and perhaps required element in the stories of the conditionally-discharged. Accounts by workers included parallel and competing versions of illness and risk, both in the present and the future.

\section{Distance and difference}

Moral rights to patient status open the way for speakers to provide progressive narratives that show movement towards recovery and non-deviant identities. The interview talk of people on conditional discharge displayed a concern to address and resolve the identity-relevant aspects of the historical self while creating the space for the performance of emerging identities. One way in which identity transition towards 
socially-valued roles was achieved was by setting up a contrast with others similarly labelled. In the following extract Tony indicated that he was different to others in the same inpatient setting because he liked to be busy. Throughout his account Tony constructed a version that worked to fore-ground his identity as a life-long worker in heavy industry.

P: Oh I found I was different, well everybody has put me down as different in any ways. Because I wanted to clean (1) or help the staff to do something. I didn't like sitting, I have never sat around innit, I worked for 41 years (1) and I've always been active so I found that even when I was in [name] prison they gave me a job as a cleaner [little laugh]. And I enjoyed buffing the floors innit, and seeing the floors, it's a job (2) so I wanted to go in the kitchens and clean, so they put me down, one of the nurses put it down [mimes writing in notes] obsessive cleanliness or something.

[Tony: Setting one: lines 709-715]

Patient participants also signalled their difference by direct allusion to dangerous behaviours of others with similar labels. For instance, Keith indicated a number of times in his account how he had shown exemplary restraint despite numerous provocations and frustrations. Indeed he goes further in establishing his difference by claims that he was able to deploy the strategies of workers and engage in correspondence with civil servants overseeing his detention.

P: But thank God you know I didn't get like um, lot of people got heavy handed and you know quite violent and things like that but I didn't use none of that and I'd even write to my case worker in the Home Office.

[Keith: Setting two: lines 18-20] 
$P: \ldots$ try to live with that stigma and that thing that you did ten years and it seems to follow you, you know, um but then we still got to assess the risks to other people and himself as we go along, that's what our job is really.

[Social worker: Setting two: lines 60-63]

Stories of mental illness and criminal offending were treated as temporally distant by patient participants and the function of the talk was to claim newer identities. The stories in these interviews had a transitory quality to them. Where previous deviant identities were acknowledged this often achieved the task of distinguishing these from newer non-deviant identity claims. The contrast between the weight of events that as culturally available information worked to impose identities upon patients and their claims to ordinariness was a striking feature of these accounts. Interestingly while service-users constructed deviant labels as historical, workers oriented towards these as current, thereby challenging emergent identity work. For example, Keith's social worker showed awareness of the difficulties of past events being brought to bear in the present but nevertheless oriented towards the possibility of present and future risk.

Lloyd's account too worked to achieve difference with his reference to the "criminals" whom he was sharing inpatient accommodation with. Categories are inference-rich and members activities category-bound (Sacks 1992). The categories of "criminals" or bad cases were used here for the purposes of establishing difference in the grading of deviance. This suggested a hierarchy of deviance in which some categories of deviance are to be seen as more serious than others.

The identity work necessarily involved in achieving community integration was an ongoing concern for patient participants. For example, one participant talked of how 
in his daily life others in society didn't know him or his history, enabling him to blend in more fully, "I go to the cinema, I'm just like a normal person" [Dave: setting 2]. Participants such as Rob, who told of how his wife had solicited opinions in the local village prior to his returning home for the purposes of gauging public reactions and Tim who was careful about disclosing information relevant to his mental ill health and offending, show that they are nevertheless still oriented to possible negative reactions;

P: There wasn't a you know I wasn't afraid to walk down you know I'm not going to hold my head high you know but certainly I wouldn't you know be staring at the floor you know umm, yeah, yeah.

[Rob: Setting two: lines 117-119]

$\mathrm{P}$ : I'm talking to people socialising, keeping, being diplomatic with the truth because obviously I don't want to mention my past you know.

[Tim: Setting two: lines 135-137]

The accounts of patient participants can be read as illustrative of the performative nature of identity work in community return within the context of ongoing concerns about living with deviant labels.

\section{Signalling emerging identities in talk}

Distance (both geographically and temporally) and difference feature in these accounts as resources to provide space for emerging identities. This identity was neither that of someone who was an institutionalised mentally ill offender nor a member of the non-mentally ill, non-criminal offending public. There was in effect 
the implication that having successfully navigated the system to achieve conditional discharge patients could then lay claim to alternative identities that were different and separate from that of someone who had not achieved discharge. These new identities were however flexible, deployed for the purposes at hand and at times, highly tentative.

The research interview may act as another venue to deploy, rehearse and refine tentative or emergent identity claims. Emerging identities were achieved in a highly consistent manner across research interviews. This was with reference to normative or culturally available roles and descriptors. For instance respondents referred to being "laid back" [Brendan, setting one] or "easy going" [Fred, setting two] or focused their talk on work or family roles [Keith, setting 2; Bryn, setting one].

P: He [the social worker] phoned me up when I had missed an appointment and he phoned me up and said you know don't you think this is the most important thing, I said no, the most important thing is my wife, my children and earning money to pay bills.

[Peter: Setting 2: lines 373-376]

P: Umm and he has had a very sort of laid back attitude really because the fact that he's you know a detained supervised patient in the community, it doesn't or has never seemed to have bothered him that much and certainly keeping to the conditions of his discharge have never, never been umm cause for concern.

[CPN: Setting 2: lines 55-59]

Participants such as Peter constructed themselves as involved in the business of everyday life. This included prioritising employment and family roles in their accounts. This may be read as providing claims to active participation in society in 
contrast with others in similar settings. These descriptions were to be seen as morally relevant and were a recurrent feature in the talk of participants. They are also a feature of everyday understandings that are used as labels for socially advantageous or desirable states when called to account for events in a research interview. That is they are identity-rich labels which are accorded valued status and as such are important orientations in talk (Antaki and Widdecombe, 1998). They denote membership of socially-valued categories and as such are important resources for the work of establishing consensus for new and emergent identities. Workers accounts, while often acknowledging this identity work, presented patients as morally ambivalent. The designation "detained supervised patient in the community" is used here to dispute Peter's claims and reassert a professional view of how he should be known.

Service-user participants clearly signalled that they were to be seen as different to other people in similar circumstances. Establishing distance in time and place from previous deviant labels and categories of people who remain so labelled achieved the task of providing sufficient room to begin new identity work in talk. For some respondents (such as those with longer periods since discharge) post-hospital identities were well developed to the extent that orientation towards older negative identity labels was almost completely absent from their talk. For those participants with more recent return to community living such as Lloyd, emerging identities in talk were less well developed, more inchoate.

\section{DISCUSSION}


An important part of micro-level analyses is examining the social practices of people engaged in these processes. An understanding of post-discharge adjustment to community life is contingent on displays of meaning, and the identities people construct. A number of socially approved vocabularies feature in the talk of participants. These include illness claims, talk of recovery and orientations to normative roles. These claims indicate the types of work that service-users do in pursuit of integration attempts. When called upon to do so, patients work to account for their actions. They do so while actively managing social sensitivities and privacy. This work is achieved in interaction and is concerned with negotiating alternative social identities as a means to overcome the negative effects of deviant labels. These aspects of the ordinary and mundane everyday experiences of social interaction are crucial to sustaining community tenure. Although similar aspects of community return have been explored with other groups (Edgerton, 1993), the hidden and hard-to-reach nature of forensic populations may be why they have largely eluded this form of investigation.

Bury (1982) has suggested that when faced with a disrupted biography individuals have to contend with the problem of future uncertainty. The illness, its symptoms and the limitations it places on their functioning tests the tolerances of others. Medical labelling of the condition will in effect warrant the behaviour of the individual, so that in some settings it will not be deemed deviant, if only temporarily, and may even be tolerated. In chronic illness the individual is prompted to re-evaluate their self-hood suggesting that identity threats are implicit in enduring ill-health.

In physical ill-health the illness and the self are conceived separately with medical 
labelling of illness an important element in allowing the individual to maintain the distance between self and illness, although as Bury (1982) indicates this line may be blurred in chronic conditions. However in mental illness the condition and the self are entwined and people struggle to establish this distance (Estroff 1989).

IIIness labels serve to help the person re-order and reconstruct experiences and as such have a role to play in bringing sense to chaotic or confusing experiences (Angermeyer and Matschinger 2003). Identifying with others who share a label may also be empowering and facilitate attempts at gaining a form of recovery (Romme, 2009).

Radley and Billig (1996) have noted that in talking about health and illness people not only exemplify their claims but also establish their social fitness. In a strictly Parsonian sense illness labels may arguably be seen to downplay agency and locate the source of troubles elsewhere, within society or within a disease process. Being sick confers both rights and obligations. The person must seek medical help and follow treatment directions in a purposeful attempt to get well and in doing so earn exemptions. These exemptions include certain role obligations such as work, relationships or more specifically responsibility for serious untoward acts such as violence or murder (Aubert and Messinger 1958). These labels can then be seen as serving moral functions in social settings, moving the person down a hierarchy of deviance from the perpetrator to the victim. As Williams (2005:130) has noted the sick role "provides both an 'insulating' and 'reintegrative' function" and is itself a form of conformity. Illness labels are also put to use by actors in interaction for these very same purposes because they are identity relevant and therefore vital for everyday dealings. These labels therefore provide a powerful resource in face-to-face 
interactions in which the person is called to account for absences from usual social requirements. Mental ill-health and criminality however are still likely to be negatively evaluated in everyday settings. So while individuals may escape the full consequences of their acts and benefit from these exemptions and the medical treatment provided, they nevertheless downplay both labels in their exchanges with others. Sickness may be an acceptable deviation in many circumstances, at least in the short-term. Mental illness particularly in its most enduring forms is not so easily accepted and when coupled with criminality embodies wider fears of chaos and dangerousness. Estroff (1989) argues that negative social reaction to mental illness has significant effects upon those experiencing these reactions to the extent that they will make efforts to manage, accommodate and reformulate interactions in their identity work.

In this study claims to illness labels by service-users were a necessary part of the story of entry to the system. These labels functioned to warrant absences from particular social requirements. For instance, they establish claims to diminished responsibility status in both legal and social settings. The disruption due to illness when prioritised in an account works to assert the moral position of the speaker. The prioritising of disruption was perhaps deployed as a counter-weight to the later revelation of offending behaviour that warranted a particularly 'sticky' deviant label.

Accounting for admission to hospital leads the person to draw on culturally available information about mental illness. This is to establish the basis for claims that they had little control over events and behaviours, which are constructed as consequent to the mental condition. When recounting admission to hospital, the offence-related 
behaviours which preceded admission are implicated and must be accounted for. To achieve this, a moral explanation is proffered which positions the speaker as a victim of both the circumstance of illness and of a system unable or unwilling to provide the care required. Maeve and Lloyds' accounts shift between constructing themselves as active agents in seeking treatment to passive actors caught up in events over which they had little control. Their responses (in the form of jumping from a bridge or setting fires) to these events can perhaps be seen as attempts at reclaiming agency. In claiming agency however there is implied moral culpability and this has to be handled carefully in the account.

It becomes necessary given the contested nature of psychiatric knowledge for participants to assert the credibility of their accounts. Aubert and Messinger (1958) have noted that any situation in which a person stands to benefit from withdrawal of role requirements as a result of illness labels will render those claims suspect. Put another way, the accounts offered in the interview talk of people on conditional discharge indicate that they are aware of social and cultural information suggesting that an illness designation arising after a crime has been committed may be questioned. As such their accounts are structured in such a way as to manage these competing accounts by describing the impact of symptoms upon their lives preceding the offences as Maeve did or like Brendan with reference to authoritative support in the form of psychiatric or legal opinion, for these claims.

Category affiliations involve potential costs as well as benefits. Snow and Andersen (1987) suggest that individuals can dissociate from a general social category or from specific groups within a category. It may be difficult however for conditionally- 
discharged people to dissociate from the general group of people classed as mentally disordered offenders. One reason for this is that they remain subject to aftercare, supervision and monitoring. Aftercare was seen as intrusive and threatening by some but at the same time the benefits associated with close attention from health and social care workers were acknowledged. Wholesale rejection of mentally disordered offender status may lead to problems in reconciling current levels of help and support. Participant's identity-work however appears to strike a balance between full acceptance and rejection of these labels. McKinlay and Dunnett highlight that talk in interaction is a means to achieve just this,

"there is a sense in which people can self-ascribe social characterisations while at the same time, avoiding the implications which go with those characterisations"

(McKinlay and Dunnett 1998:36)

Identity is achieved in interaction with other social actors and remains open to negotiation and revision. To achieve social reintegration following conviction and detention in forensic services, the person must produce identity displays which are viable. These displays must achieve acceptable accommodations so that the individual can build new social identities as they attempt to live outside of hospital. Identity performance following discharge is crucial for smoothing transition and establishing tenure in social settings beyond the institution. Conditionally-discharged people, called to account for the circumstances of their discharge in a research interview, demonstrate "indexical, local and occasioned" talk that functions to deploy normative identities (Widdicombe 1998:195). 


\section{CONCLUSION}

The transition of people through the forensic mental health system involves the imposition of roles by a combination of law and psychiatry but they also imply changes in how the person is to be known more widely (Aubert and Messinger, 1958). There is a sense that these transitions have a rites of passage quality to them but they also differ in a number of important ways (van Gennep 1960; Turner 1969). For example, they are not usually actioned by the involved individuals themselves but imposed by others. The transition is also not one which fits with the expectations of individuals with regard to their life trajectory. They are cast as biographical disruptions by participants, and lead to prolonged attempts by the individual at restoring a form of stasis.

These transitions do not have the same weight of public or collective support that may be seen in celebrations of puberty or birth in tribal rites of passage. In many ways they are hidden, often strategically and tactically from public view by workers, families and the person themselves. For instance, they take place in distant institutions, surrounded by high walls and fences to maintain security and to discourage public scrutiny. Transition events are effectively cloaked in secrecy by workers, a combination of real concerns for confidentiality and a historical, professional culture that is concerned with privileged access to information (Mercer and Mason, 1998).

The individual has to go about the work of accomplishing new identities in new social settings. Identities achieved, in the relative safety of a closed environment, must then be handled in interaction with the wider community. Deviance in the form of 
criminal offending, mental illness and incarceration must be reconciled with the societal requirements of normative behaviour. The person is challenged in their everyday contact with the wider community, to accomplish identities and to sustain these in the face of competing available labels that are liable to be imposed upon them by others in society. The requirements to pass, manage sensitive identitythreatening information and to determine when disclosure or privacy is appropriate form an important element of their social practice.

\section{REFERENCES}

Adshead G. \& Brown C. (2003) Ethical issues in forensic mental health research London: Jessica Kingsley.

Annandale E. (1996) Working on the front-line: risk culture and nursing in the new NHS, Sociological Review, 44(3): 416-51.

Angermeyer, M.C. \& Matschinger, H. (2003) The stigma of mental illness: Effects of labelling on public attitudes towards people with mental disorder. Acta Psychiatrica Scandinavica, 108(4), 304-309.

Antaki C. and Widdicombe S. (Eds.) (1998) Identities in Talk. London: Sage Publications.

Atkinson P. (1997) Narrative turn or blind alley? Qualitative Health Research, 7: 325344. 
Atkinson, P. (1995). Medical talk and medical work: The liturgy of the clinic. London: Sage Publications.

Aubert V. \& Messinger S. (1958) The Criminal and the Sick. Inquiry, 1, 137-160.

Becker H. S. (1963) Outsiders: Studies in the sociology of deviance. New York: The Free Press.

Benwell B. and Stokoe E. (2006) Discourse and ldentity. Edinburgh: Edinburgh University Press.

Brannen J. (1988) The study of sensitive subjects. Sociological Review, 36: 552-563.

Breggin P. (1993) Toxic psychiatry: Why therapy, empathy and love must replace the drugs, electroshock and biochemical theories of the new psychiatry, St Martin's Press: New York.

Bury M. (1982) Chronic illness as biographical disruption. Sociology of Health \& IIIness, 4(2): 167-182.

Carpenter W.T., Jr, Gold J.M., Lahti A.C., Queern C.A., Conley R.R., Bartko J.J., Kovnick J. \& Appelbaum P.S. (2000): Decisional Capacity for Informed Consent in Schizophrenia Research. Archives of General Psychiatry, 57, 533-538. 
Coffey, M. (2008) Accomplishing being ordinary: identity talk of people conditionallydischarged from secure forensic settings. PhD Thesis. Swansea: Swansea University.

Crossley N. (2006) The field of psychiatric contention in the UK, 1960-2000. Social Science \& Medicine 62(3): 552-563.

Department of Health (1983) The Mental Health Act 1983. London: Department of Health.

Double D. (2002) The limits of psychiatry. British Medical Journal, 324: 900-904.

Edgerton R.B. (1993) The cloak of competence. Berkley and Los Angeles: University of California Press.

Edwards D. (2006) Narrative analysis. In Jaworski A. and Coupland N. (Eds) pp. 227-238, The Discourse Reader. London: Routledge.

Edwards D. (1998) The relevant thing about her: Social identity categories in use. In Antaki C. and Widdicombe S. (eds.) pp. 15-33, Identities in talk. London: Sage Publications.

Edwards, D. and Potter, J. (1992) Discursive Psychology, London: Sage. 
Estroff S. E. (1989) Self, identity, and subjective experiences of schizophrenia: In search of the subject. Schizophrenia Bulletin, 15(2): 189-196.

Farmer P. (1996) On suffering and structural violence: A view from below. Daedalus, 125(1): 261-283

Garfinkel H. (1967) Studies in ethnomethodology, Englewood Cliffs, New Jersey: Prentice-Hall.

Gibbens T. C. N. \& Robertson G. (1983) A survey of the criminal careers of hospital order patients. British Journal of Psychiatry, 143(4): 362-369.

Goffman, E. (1963) Stigma: Notes on the management of spoiled identity. New Jersey: Prentice-Hall Inc.

Heritage J. and Atkinson J.M. (1984) Introduction. In Atkinson J.M. and Heritage J. (Eds,) pp.1-16, Structures of social action: Studies in conversational analysis. Cambridge: Cambridge University Press.

Jarvinen M. (2000) The biographical illusion: Constructing meaning in qualitative interviews. Qualitative Inquiry 6(3), 370-391

Kelly B. D. (2005) Structural violence and schizophrenia. Social Science \& Medicine, 61(3): 721-730. 
Lee R. M. (1993) Doing research on sensitive topics. London: Sage Publications.

Lemert E. M. (1972) Human deviance, social problems, and social control Englewood Cliffs, N.J.: Prentice-Hall,

Maden A., Curle C., Meux C., Burrow S. \& Gunn J. (1993) The treatment and security needs of patients in special hospitals. Criminal Behaviour \& Mental Health. 3, 290-306.

McKinlay A. and Dunnett A. (1998) How gun owners accomplish being deadly average. In Antaki C. and Widdicombe S. (Eds.) pp. 34-51, Identities in talk. London: Sage Publications.

Mercer D. \& Mason T. (1998) From devilry to diagnosis: the painful birth of forensic psychiatry. In Mason T. and Mercer D. (Eds.) pp. 9-30, Critical Perspectives in Forensic Care. Basingstoke: MacMillan.

Orbuch T. L. (1997) People's accounts count: The sociology of accounts. Annual Review of Sociology, 23: 455-78.

Parsons T. (1951) The social system. Glencoe, Illinois: The Free Press.

Radley A., and Billig M. (1996) Accounts of Health and IIIness: dilemmas and representations. Sociology of Health and IIIness, 18(2): 220-240. 
Romme, M. (2009) Hearing voices groups in Romme, M., Escher, S., Dillon, J., Corstens, D. and Morris, M. (eds) pp.73-85 Living with voices: 50 stories of recovery. Ross-on-Wye: PCCS Books.

Sacks H. (1992) Lectures in conversation. Oxford: Blackwell Science.

Sieber J. E. and Stanley B. (1988) Ethical and professional dimensions of socially sensitive research. American Psychologist, 43(1): 49-55.

Scott M. B. and Lyman S.M. (1968) Accounts. American Sociological Review. 33(1): 46-62.

Snow D. A. and Andersen L. (1987) Identity work among the homeless: The verbal construction and avowal of personal identities. The American Journal of Sociology. 92(6): 1336-1371.

Stanley S. and Billig M. (2004) Dilemmas of story-telling and identity. In Daiute C. and Lightfoot C. (Eds.) pp. 159-176. Narrative analysis: Studying the development of individuals in society. Thousand Oaks, California: Sage Publications.

Turner V. W. (1969) The ritual process: Structure and anti-structure. London: Routledge and Kegan Paul.

van Gennep A. (1960) The rites of passage: A classical study of cultural celebrations. London: Kegan Paul and Routledge. 
Widdicombe, S. (1998) Identity as an analysts' and a participants' resource. In Antaki, C. and Widdicombe, S. (Eds.) pp. 191-206. Identities in talk. London: Sage Publications.

Williams S.J. (2005) Parsons revisited: from the sick role to...? Health, 9(2): 123144.

\section{TRANSCRIBING CONVENTIONS}

[????] $\quad$ inaudible word or passage of speech

[drinks coffee] description of participant action during research interview over[lap square brackets between adjacent lines indicate beginning overlap] and end of hear-able overlapping talk underlined underlined words or part of words denote emphasis placed by the speaker timed pauses to the nearest complete second

Uh or umm Sounds uttered by participants in the course of their speech Omission of a part of the transcript

worUse of a hyphen appended to an incomplete word indicates a sharp cut-off of the word or sound

l: $\quad$ Denotes interviewer

P: $\quad$ Denotes participant 